University of Nebraska - Lincoln

DigitalCommons@University of Nebraska - Lincoln

Agronomy \& Horticulture - Faculty Publications

Agronomy and Horticulture Department

10-2001

\title{
'Forrest' Resistance to the Soybean Cyst Nematode Is Bigenic: Saturation Mapping of the Rhg1 and Rhg4 Loci
}

\author{
K. Meksem \\ Southern Illinois University, meksemk@siu.edu \\ P. Pantazopoulos \\ Southern Illinois University \\ V. N. Njiti \\ Southern Illinois University \\ D. L. Hyten \\ Southern Illinois University, david.hyten@unl.edu \\ P. R. Arelli \\ University of Missouri - Columbia, prakash.arelli@ars.usda.gov
}

See next page for additional authors

Follow this and additional works at: https://digitalcommons.unl.edu/agronomyfacpub

Part of the Agricultural Science Commons, Agriculture Commons, Agronomy and Crop Sciences

Commons, and the Plant Breeding and Genetics Commons

Meksem, K.; Pantazopoulos, P.; Njiti, V. N.; Hyten, D. L.; Arelli, P. R.; and Lightfoot, D. A., "'Forrest'

Resistance to the Soybean Cyst Nematode Is Bigenic: Saturation Mapping of the Rhg1 and Rhg4 Loci"

(2001). Agronomy \& Horticulture -- Faculty Publications. 774.

https://digitalcommons.unl.edu/agronomyfacpub/774

This Article is brought to you for free and open access by the Agronomy and Horticulture Department at DigitalCommons@University of Nebraska - Lincoln. It has been accepted for inclusion in Agronomy \& Horticulture -Faculty Publications by an authorized administrator of DigitalCommons@University of Nebraska - Lincoln. 


\section{Authors}

K. Meksem, P. Pantazopoulos, V. N. Njiti, D. L. Hyten, P. R. Arelli, and D. A. Lightfoot 
Published in Theoretical and Applied Genetics 103:5 (October 2001), pp. 710-717;

doi: $10.1007 /$ s001220100597

Copyright (C) 2001 Springer-Verlag. Used by permission.

Submitted November 5, 2000; accepted January 23, 2001.

\title{
'Forrest' Resistance to the Soybean Cyst Nematode Is Bigenic: Saturation Mapping of the Rhg1 and Rhg4 Loci
}

\author{
K. Meksem, ${ }^{1}$ P. Pantazopoulos, ${ }^{1}$ V. N. Njiti, ${ }^{1}$ D. L. Hyten, ${ }^{1}$ P. R. Arelli, ${ }^{2}$ and \\ D. A. Lightfoot ${ }^{1}$
}

1. Department of Plant Soil and General Agriculture, Center for Excellence in Soybean Research, Teaching and Outreach, Southern Illinois University at Carbondale, Room 176, Carbondale, IL 62901-4415, USA

2. Department of Agronomy, 104 Curtis Hall. University of Missouri, Columbia, MO 65211, USA

Corresponding author - K. Meksem, email meksemk@siu.edu

\begin{abstract}
Field resistance to cyst nematode (SCN) race 3 (Heterodera glycines I.) in soybean [Glycine max (L.) Merr.] cv 'Forrest' is conditioned by two QTLs: the underlying genes are presumed to include Rhg1 on linkage group G and Rhg4 on linkage group A2. A population of recombinant inbred lines (RILs) and two populations of near-isogenic lines (NILs) derived from a cross of Forrest $\times$ Essex were used to map the loci affecting resistance to SCN. Bulked segregant analysis, with 512 AFLP primer combinations and microsatellite markers, produced a high-density genetic map for the intervals carrying Rhg1 and Rhg4. The two QTLs involved in resistance to SCN were strongly associated with the AFLP marker EatgMcGa87 $\left(P=0.0001, \mathrm{R}^{2}=24.5 \%\right)$ on linkage group $\mathrm{G}$, and the AFLP marker EccGMAac405 $\left(P=0.0001, \mathrm{R}^{2}=26.2 \%\right)$ on linkage group A2. Two-way analysis of variance showed epistasic interaction $\left(P=0.0001, \mathrm{R}^{2}=16 \%\right.$ ) between the two loci controlling SCN resistance in Essex $\times$ Forrest recombinant inbred lines. Considering the two loci as qualitative genes and the resistance as female index FI $<5 \%$, jointly the two loci explained over $98 \%$ of the resistance. The locations of the two QTLs were confirmed in the NILs populations. Therefore SCN resistance in Forrest $\times$ Essex is bigenic. High-efficiency marker-assisted selection can be performed using the markers to develop cultivars with stable resistance to SCN.
\end{abstract}


Keywords: soybean cyst nematode, AFLP, high-resolution genetic mapping, marker-assisted breeding, Rhg1, Rhg4, qualitative mapping

\section{Introduction}

The soybean cyst nematode (SCN), Heterodera glycines, is a widespread pest of soybeans and causes substantial yield losses worldwide (Wrather et al. 1996). Soybean plant introductions that are resistant to SCN suppress reproduction of the nematode but do not eliminate damage (Rao-Arelli and Anand 1988). During selection, SCN populations often develop the ability to overcome resistance (Riggs and Schmidt 1988).

Resistance to SCN is often found in unadapted germplasm and the genetics of resistance can be complex (Rao-Arelli et al. 1992). Transfer of the underlying genes to adapted germplasm is a laborious process since the resistance phenotype is oligogenic and quantitative. Furthermore, introgression may be complicated by linkage drag on yield (Mudge et al. 1996) and variability in the pathogen population (Riggs and Niblack 1999). DNA markers detect loci underlying resistance to SCN as QTLs (Webb et al. 1995; Concibido et al. 1996; Chang et al. 1997). DNA markers within 1-5 cM of the loci can be used to select for resistance during soybean breeding (Prabhu et al. 1999). Compared to phenotypic selection, DNA markers expedite gene introgression, minimize linkage drag, and maximize recovery of the target genome.

There are very few different sources for soybean cyst nematode resistance genes and their alleles in the U.S. soybean crop (PI 88788, PI 437.654, Peking, PI90763 and PI209332). More than $85 \%$ of SCN-resistant cultivars are derived from PI88788 due to superior agronomic performance (Skorupska et al. 1994). DNA marker analysis has shown that resistance to SCN was quantitative when derived from PI437654 (Webb et al. 1995; Vierling et al. 1997; Prabhu et al. 1999), Peking (Mahalingam and Skorupska 1995; Chang et al. 1997), PI88788 (Concibidio et al. 1997; Matthews et al. 1998), PI90763 and PI209332 (Concibidio et al. 1996, 1997). One locus, on linkage group G, is common among the sources of resistance to SCN and is thought to correspond to rhg1 that was identified by classical genetics as a recessive gene (Rao-Arelli et al. 1992). Among crosses deriving resistance to SCN from Peking and PI437654, the second locus on linkage group A2 is thought to correspond to Rhg4. Rhg4 was originally identified by classical genetics (Myers and Anand 1991; RaoArelli et al. 1992). Other loci (Qiu et al. 1999) implicated in resistance to SCN differ by their position on the genetic map (linkage groups B, E, F, H, I and J) and the nature of the pathogen population to which they confer resistance (often categorized as race 1, 3, 5 or 14) (Riggs and Schmidt 1988). These QTLs have not been confirmed in multiple mapping studies.

When multiple QTLs segregate, the error associated with inference of a QTL may be inflated by the effects of the other QTLs, recombination, non-genetic variation and errors in scoring (Kearsey and Farquhar 1998). Furthermore, linked QTLs can cause biased estimates of QTL position. Using methods of QTL analysis that can simultaneously account for multiple QTLs (Knapp and Bridges 1990) it is possible to create a model that contains parameters for multiple QTLs and simultaneously estimate the most-likely positions of QTLs within two or more intervals (Knott and Haley 1992). QTL analysis can show the 
presence of linked or coincident QTLs for target and non-target traits (Tanksley and Nelson 1996). Although linkage and pleiotropy may be indistinguishable at the level of resolution afforded by common population sizes and marker densities, information regarding the frequency of coupling vs repulsion relationships can be invaluable in developing a breeding strategy.

The development of SCN-resistant soybean cultivars with durable resistance is a complex challenge for breeders due to the multiple QTLs, the resistance sources and the SCN populations involved. Breeding for quantitative traits by marker-assisted selection can be further complicated unless a large number (3-5) of markers tightly linked $(>1 \mathrm{cM})$ to loci conferring SCN resistance are available. Sufficient marker density can be developed by high-resolution mapping of the QTLs conferring resistance to SCN (Meksem et al. 1999) and targeted marker development (Meksem et al. 1998, 2000a; Cregan et al. 1999). In this report we have focused on SCN resistance in cv 'Forrest,' derived from Peking, reported to be inherited quantitatively due to segregation of two QTLs (Chang et al. 1997). The two QTLs were fine-mapped using AFLP and bulked segregant analysis. Using the closest markers $(0.5-1 \mathrm{cM})$ to each gene, Mendelian inheritance of Rhg1 and Rhg4 was examined and the positions of the two QTLs were confirmed using nearisogenic lines.

\section{Materials and methods}

\section{Plant material}

A population of $100 \mathrm{~F}_{5}$ derived recombinant inbred lines (RILs) from the cross 'Essex' (Smith and Camper 1973) × 'Forrest' (Hartwig and Epps 1973) was used to construct a genetic linkage map. Forrest is resistant to the soybean cyst nematode ( $\mathrm{SCN}$ ) while Essex is susceptible. Forrest derived its resistance to SCN from Peking. Soybean seeds derived from F:13 recombinant inbred lines were planted at the agronomy research center, Southern Illinois University, Carbondale, in a soil defined as Stoy Fine-silty, mixed, mesic, Aquic, Hapludalfs (Hnetkovsky et al. 1996). Soybean genomic DNA was extracted from a pooled sample of leaves from five plants per genotype. The RILs were advanced to the F5:13 generation from never less than 300 plants per RIL per generation during these studies.

Fine mapping of genes controlling the SCN resistance was performed in two nearisogenic line (NIL) populations, $\mathrm{E} \times \mathrm{F} 6$ and $\mathrm{E} \times \mathrm{F} 34$, that were developed from 40 individual plants at the F5:9 generation from within heterogeneous RILs by plant seed-to-row descent (Njiti et al. 1998; Meksem et al. 1999, 2000c). E × F34 segregated for a region encompassing Rhg1 on linkage group G (Meksem et al. 1999). E $\times$ F6 segregated for a region encompassing Rhg4 which derives resistance to SCN on linkage group A2. Individual NILs from E $\times$ F34, line 6 (Resistant line) and line 29 (Susceptible line) were crossed to produce F1 and F2 populations.

Soybean genomic DNA used for AFLP and microsatellite analysis was extracted and purified using the Qiagen Plant Easy DNA Extraction Kit (Qiagen, Hilden, Germany).

\section{DNA probes and microsatellite primers}

The Bng122 RFLP probe was provided by Dr. E. Vallejos (University of Florida, USA). The microsatellite primers (BARC-Satt 309, BARC-Satt 275, and BARC-Satt 163) were provided 
by Dr. P. Cregan (USDA, Beltsville, Md., USA). The rest of the soybean Map-pair primers were purchased from Research Genetics (Huntsville, Ala., USA). The microsatellite primers for SIUC-SAT122 (table 1) were generated at SIUC from a BAC clone (Meksem et al. 1998, 2000a). The pBLT65 primers were provided by Dr. B. Matthews (USDA, Beltsville Md., USA). The RAPD markers OIO3, OG13, OW15 and the RFLP K636V marker were described in Chang et al. (1997).

\begin{tabular}{|c|c|c|c|}
\hline Primers & & $n$ & $5^{\prime} \gg \gg \gg \gg 3^{\prime}$ \\
\hline \multirow[t]{2}{*}{ SIUC-Sat122 } & forward & 1 & CTCACAAAATTGAAATGTATC 3' \\
\hline & reverse & 1 & ССТTTTTCATCTTGAAAAT 3' \\
\hline $\mathrm{EA} / \mathrm{C}$ & & 2 & AGACTGCGTACCAATTC+A/C \\
\hline $\mathrm{M}_{\mathrm{A} / \mathrm{C}}$ & & 2 & GACGATGAGTCCTGAGTAA+A/C \\
\hline$E+3$ & & $16 \times 2$ & GACTGCGTACCAATTCA/C+NN \\
\hline $\mathrm{M}+3$ & & $16 \times 2$ & GATGAGTCCTGAGTAAA/C+NN \\
\hline
\end{tabular}

\section{Microsatellite markers}

The microsatellites primers were labeled by phosphorylating the $5^{\prime}$ end with $5 \mu 1$ of $\left[\gamma-{ }^{32} \mathrm{P}\right]$ ATP $\left(3000 \mathrm{Ci} / \mathrm{mmol}\right.$ ) for $30 \mathrm{~min}$ at $37^{\circ} \mathrm{C}$ with ten units of T4 kinase (Pharmacia, Piscataway, N.J.). Radioactive PCR reactions (Meksem et al. 1999) were performed with genomic DNA from the mapping populations. The PCR products were separated by electrophoresis on a $5 \%(\mathrm{w} / \mathrm{v})$ polyacrylamide denaturing gel and visualized by exposing X-ray film to the dried gel.

\section{AFLP markers}

AFLP analysis was performed as described by Vos et al. (1995) with minor modifications (omitting the streptavidin bead selection step). Briefly, primary template DNA was prepared using the restriction enzymes EcoRI and MseI. PCR reactions were performed with EcoRI/MseI-digested ligated DNA using two sets of primers (table 1). Primers within set EcoRI all included the sequence 5'-GAC TGC GTA CCA ATT C; primers of the MseI set have the sequence 5'-GAT GAG TCC TGA GTA A. The primer combinations EA/MC and EC/MA were used for pre-amplification of the primary template. Six selective nucleotides were used to generate AFLP fragments from the secondary template. A total of 512 primer combinations were used in this study.

\section{DNA pool for BSA (bulked segregant analysis)}

Genomic DNA from Essex, Forrest and pools of two different genotypic classes each derived from eight RILs were used (fig. 1). The two pools contrasted for the regions thought to encompass both QTLs for resistance to SCN on linkage group G and on linkage group A2. The first DNA pool was constructed from eight RILs that were resistant to SCN and had Forrest alleles at markers BARC-Satt214, BARC-Satt309, and Bng122 (a 10-cM interval on linkage group G) and pBLT65 and OW15, pBLT65 and K636V (a 35-cM interval on link- 
age group A2). The second DNA pool was constructed from eight RILs that were susceptible to SCN and had the Essex allele at markers BARC-Satt214, BARC-Satt309 and Bng122, and pBLT65 and OW15, pBLT65 and K636V.
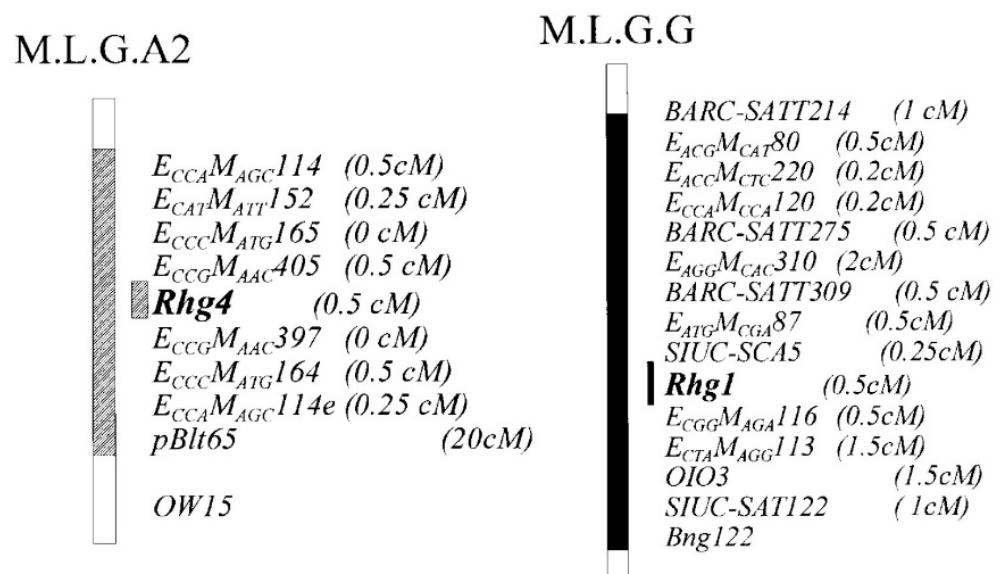

Figure 1. High-density genetic map of the chromosomal segments carrying the Rhg1 and Rhg4 loci. M.L.G.=molecular linkage group

Each pool contained recombination events in each of the targeted linkage groups. Two of the eight RILs in the resistant pool contained recombination events in the interval between marker loci BARC-Satt214 and BARC-Satt 309 on linkage group G, and four of them were recombination events in the interval between marker loci pBLT65 and K636V on linkage group A2. In the susceptible pool two RILs contained recombination events in the interval between marker loci BARC-Satt214 and BARC-Satt309, and four contained recombination events between pBLT65 and OW15.

\section{SCN female index (FI) determination}

The number of white female cysts was compared on each genotype to the number of white female cysts on a susceptible control Essex to determine the female index (FI) for each population. The FI was performed on seedlings at the University of Missouri-Colombia by inoculating the genotypes with $2000 \pm 25$ eggs from a homogenous isolate of $\mathrm{H}$. glycines. The population was 'race 3 ' as determined by the FI on Peking (1.2\%), Pickett $(1.8 \%)$, PI88788 (3.0\%), PI90763 (1.2\%), and PI437654 (1.2\%). All experiments used five single-plant replications per NIL. The mean number of white female cysts on each genotype and the susceptible control were determined and FI was calculated as the ratio of the mean number of cysts on each genotype to the mean number of cysts on the susceptible check.

\section{Detecting loci associated with quantitative resistance}

To detect genomic regions associated with SCN resistance, the recombinant inbred lines were classified as a Forrest (B) allele or an Essex (A) allele for each marker. The heterogeneous lines (5-13 lines per marker) were excluded for RFLP, AFLP, and microsatellite 
markers but could not be identified or excluded from the RAPD data. Markers were compared with SCN disease response scores (FI) by a one-way analysis of variance (ANOVA) performed with SAS (SAS Institute Inc., Cary, N.C., Wang et al. 1994). The probability of association of each marker with the trait was determined and a significant association was declared if $P<0.005$, to maximize the detection of associations (Lander and Botstein 1989).

\section{Detecting interactions between quantitative resistance loci}

Selected pairs of markers were analyzed by the two-way ANOVA PROC GLM procedure to detect non-additive interactions between the unlinked QTLs (Lark et al. 1995). Nonadditive interactions between markers which were significantly associated with SCN response were excluded when $P>0.05$. Selected groups of markers were analyzed by multiway ANOVA to estimate joint heritabilities for traits associated with multiple QTLs. Joint heritability was determined from the model R2 term in a multi-way ANOVA.

\section{Mapping quantitative and qualitative resistance loci}

Mapmaker-EXP 3.0 (Lander et al. 1987) was used to calculate map distances [centimorgans (cM), Haldane units] between linked markers and to construct a linkage map. The recombinant inbred line (ri-self) genetic model was used. The $\log _{10}$ of the odds ratio (LOD) for grouping markers was set at 2.0, and the maximum distance was $30 \mathrm{cM}$. Conflicts were resolved in favor of the highest LOD score after checking the raw data for errors. Marker order within groups was determined by comparing the likelihood of many map orders. A maximum-likelihood map was computed with error detection. Groups were assigned to linkage groups by anchored microsatellite and RFLP markers (Shoemaker and Specht 1995; Cregan et al. 1999).

The map and SCN disease data were simultaneously analyzed with Mapmaker/QTL 1.1 (Paterson et al. 1988) using the $\mathrm{F}_{2}$-backcross genetic model for trait segregation (Webb et al. 1995; Hnetkovsky et al. 1996; Chang et al. 1996, 1997). Putative QTLs were inferred when LOD scores exceeded 3.0 at some point in each interval since this was found empirically to be equivalent to a single marker $P<0.005$, the criterion used in the one-way ANOVA. The positions of the QTLs were inferred from the interval peak LOD score.

\section{Results}

\section{Identification and mapping of tightly linked AFLP markers}

AFLP markers linked to the Rhg1 and Rhg4 loci were identified by analysis of Essex, Forrest, a pool of susceptible RILs and a pool of resistant RILs. A total of 512 primer combinations were used. About 72 fragments were detected per primer combination for a total of 36800 loci screened. The frequency of polymorphism between Essex and Forrest was 6.5\% but ranged from 3 to $12 \%$ depending on the primer combination tested. Out of 2396 loci polymorphic between Essex and Forrest, 83 were polymorphic between the pool of susceptible RILs and the pool of resistant RILs. Seven markers were linked to the SCN locus on G in coupling, two of which were codominant. Seven markers were linked to the SCN locus on A2, six were derived from co-dominant markers that provided three markers in coupling (fig. 2). The other 69 loci mapped to different linkage groups in $\mathrm{E} \times \mathrm{F}$. 


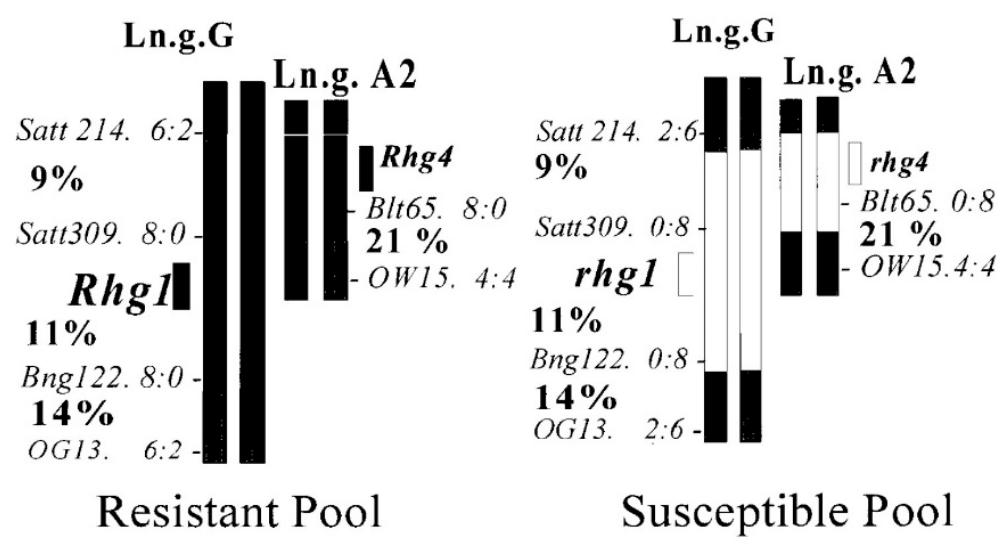

Figure 2. Pools constructed for bulked segregant analysis.

\section{DNA markers associated with the female index}

A one-way analysis of variance detected two independent genomic regions on two linkage groups $(P<0.005)$ with effects on SCN disease. Molecular linkage groups $\mathrm{G}$ and $\mathrm{A} 2$ each contained one QTL for resistance to SCN.

A region on linkage group $\mathrm{G}$ (fig. 2) encompassing about $7 \mathrm{cM}$ from BARC-Satt275 to Bng122 was found to contain a major QTL for SCN FI $\left(P=0.0001, \mathrm{R}^{2}=24.49\right)$ that derived the beneficial allele from Forrest. The interval had a peak LOD score of 5.1 at the EatGMcGa87 marker and explained about $25 \%$ of the total variation in SCN FI (table 2) in the $\mathrm{E} \times \mathrm{F}$ recombinant inbred line population. Using the $\mathrm{E} \times \mathrm{F} 34$ NIL population to fix the second QTL on A2, the marker was associated with a QTL on G that explained $98 \%(P=$ 0.0001) of the total variation (table 3).

Table 2. DNA markers associated with loci underlying SCN resistance in the Essex $\times$ Forrest recombinant inbred line population.

L.G.=linkage group; FI: female Index

\begin{tabular}{|c|c|c|c|c|c|c|c|}
\hline \multirow[t]{2}{*}{ DNA marker } & \multirow[t]{2}{*}{ L.G. } & \multirow[t]{2}{*}{$\mathrm{R}^{2}$} & \multirow[t]{2}{*}{$P>\mathrm{F}$} & \multirow[t]{2}{*}{$\mathrm{LOD}^{\mathrm{a}}$} & \multirow[t]{2}{*}{ QTL var. ${ }^{b}$} & \multicolumn{2}{|c|}{$\begin{array}{l}\text { Mean FI }(\%) \forall \text { SEM for } \\
\text { RILs with alleles from }\end{array}$} \\
\hline & & & & & & Forrest & Essex \\
\hline EAtgMcGa87 & G & 24.49 & 0.0001 & 5.1 & 24.1 & $38 \pm 5$ & $70 \pm 3$ \\
\hline BARC-Satt309 & G & 15.7 & 0.0002 & 3.2 & 15.3 & $43 \pm 6$ & $68 \pm 3$ \\
\hline pBLT65 & A2 & 22.09 & 0.0001 & 4.9 & 21.4 & $35 \pm 5$ & $66 \pm 3$ \\
\hline ECCGMAAC417 & $\mathrm{A} 2$ & 26.2 & 0.0001 & 5.2 & 24.6 & $34 \pm 6$ & $68 \pm 3$ \\
\hline
\end{tabular}

$\mathrm{a}=\mathrm{LOD}$ is indicative of the probability based on the presence of a locus, not on the absence; LOD threshold $=3.0$

$\mathrm{b}=$ Amount of variability in the trait explained by the marker loci based on MapMaker QTL 
Table 3. DNA markers associated with disease resistance in the $\mathrm{E} \times \mathrm{F} 34$ - and $\mathrm{E} \times \mathrm{F} 6$-derived near-isogenic line populations.

L.G.=linkage group; FI: female Index

\begin{tabular}{llccccc}
\hline NIL & DNA marker & L.G. & $\mathrm{R}^{2}$ & $P>\mathrm{F}$ & \multicolumn{2}{c}{$\begin{array}{c}\text { Mean FI (\%) } \forall \text { SEM for NIL } \\
\text { with alleles from }\end{array}$} \\
\cline { 5 - 7 } & & & & & Forrest & Essex \\
\hline E $\times$ F34 & EATGMcGA87 & G & 98.4 & 0.0001 & $2 \pm 2$ & $51 \pm 3$ \\
$\mathrm{E} \times \mathrm{F} 6$ & EccGMAAC417 & A2 & 99.2 & 0.0001 & $2 \pm 2$ & $63 \pm 6$ \\
\hline
\end{tabular}

The QTL for resistance to SCN on linkage group A2 (fig. 3), was $4 \mathrm{cM}$ from pBLT65EccAMAGC114. The AFLP marker ECCGMAAC 417 was strongly associated with resistance to $\operatorname{SCN}\left(P=0.0001, \mathrm{R}^{2}=26.2\right)$ and derived the beneficial allele from Forrest (table 2$)$. The interval had a peak LOD score of 5.2 and explained about $26 \%$ of the total variation in the SCN FI (table 2) in the $\mathrm{E} \times \mathrm{F}$ recombinant inbred line population. The marker was associated with a QTL on linkage group A2 that explained $99 \%$ of the variation in the $\mathrm{E} \times \mathrm{F} 6 \mathrm{NILs}$ population (table 3).

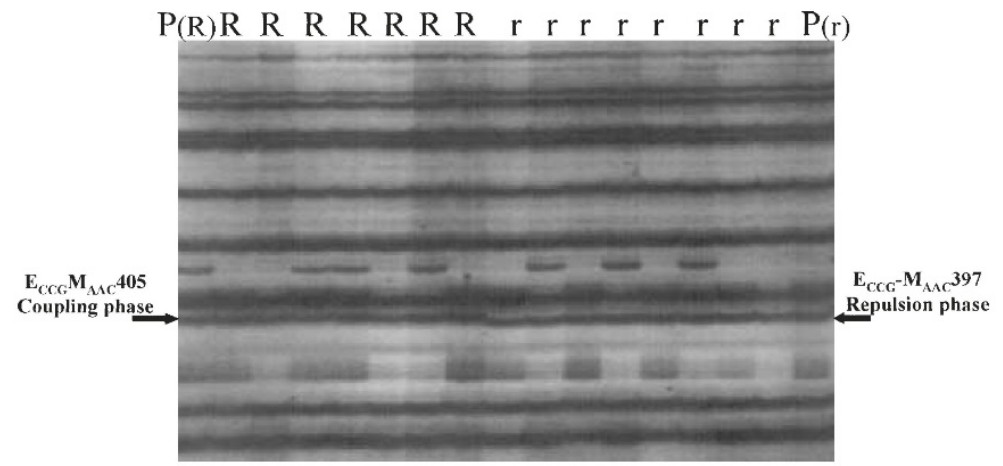

Figure 3. Phenotype of the AFLP marker EccGMaAc405 linked with Rhg4. $P(R)$ : resistant parent (Forrest); $P(r)$ susceptible parent (Essex). $R$ resistant line, $r$ susceptible line.

\section{Interaction among loci contributing to SCN resistance in the RILs}

A two-way analysis of variance detected a significant interaction $(P<0.005)$ among the two loci contributing most strongly to $\mathrm{SCN}$ resistance in this population (table 5). Jointly, the two QTLs explained about $65 \%$ of the total variation in FI data in the $\mathrm{E} \times \mathrm{F}$ recombinant inbred line population. 
Table 4. Soybean cyst nematode (SCN) race 3 female-index (FI) means among the $\mathrm{E} \times \mathrm{F}$ recombinant inbred lines when the two closest markers to Rhg1 and Rhg4 are combined. E: Essex allele; F: Forrest allele (beneficial allele); N: number of lines; FI: female Index

\begin{tabular}{cccc}
\hline EatGMcGa87 & EccGMaAc405 & N & Mean FI (\%) \pm SEM for RILs \\
\hline E & E & 25 & $73 \pm 4$ \\
F & E & 24 & $62 \pm 6$ \\
E & F & 17 & $66 \pm 5$ \\
F & F & 18 & $5 \pm 2$ \\
\hline
\end{tabular}

Table 5. Recombinants identified with the AFLP markers flanking Rhg1 on linkage group G and Rhg4 on linkage group A2

\begin{tabular}{|c|c|c|c|c|c|}
\hline \multirow[t]{2}{*}{ Population } & \multirow[t]{2}{*}{ Size } & \multicolumn{2}{|c|}{ Rhg4 } & \multicolumn{2}{|c|}{ Rhg1 } \\
\hline & & ECCGMAAC405 & ECCGMAAC397 & EATGMCGA 87 & ECGGMAGA116 \\
\hline $\mathrm{E} \times \mathrm{F}$ & 100 & 1 & 1 & 1 & 1 \\
\hline $\mathrm{E} \times \mathrm{F} 34$ & 200 & - & - & 2 & 3 \\
\hline $\mathrm{E} \times \mathrm{F} 6$ & 200 & 2 & 2 & - & - \\
\hline Totals & 500 & 3 & 3 & 3 & 4 \\
\hline
\end{tabular}

All four expected allelic-class combinations were observed. All recombinant inbred lines with Forrest alleles (EATGMcGA87, EccGMaAC405) at both loci were resistant to SCN (FI of 0-5). Recombinant inbred lines that had one Forrest allele and one Essex allele at loci (A2 and G) showed a high SCN FI that was not significantly different from lines with Essex alleles at both loci (table 5).

\section{Mapping Rhg1 and Rhg4 as qualitative loci}

The strong association between marker and phenotype suggested that the QTLs might be mapped as qualitative loci, Rhg1 and Rhg4. When mapping Rhg1 in the RIL population the marker EccGMaAC405 was used to fix the allele at Rhg4. When mapping Rhg4 in the RIL population the marker EATGMCGA87 was used to fix the allele at Rhg1. Initial mapping of these markers in the RIL population of 100 individuals indicated that EccGMAAC405 and EccGMaAc405 flank Rhg4, and EatgMcga87 and EcggMaga116 flank Rhg1 (fig. 2). Additional mapping populations analyzed using these four AFLP markers identified 2-3 additional recombinants between each gene and the nearest flanking markers, and allowed the map distances to be refined (table 5, fig. 2).

Several near-isogenic lines were identified that were heterogeneous within intervals that encompassed the genes. Individual plants within such lines were known to be segregating for Rhg1 (Meksem et al. 1999). In addition, plants heterozygous around Rhg1 (Rhg1rhg1Rhg4Rhg4) were identified in the F2 generation of a cross between SCN susceptible NIL E × F34-29 (rhg1rhg1Rhg4Rhg4) and SCN resistant NIL E × F34-6 (Rhg1Rhg1Rhg4Rhg4). We examined the SCN FI of NILs that were heterozygous (table 6). The observed segregation ratio did not deviate significantly $(P>0.05)$ from the phenotypic ratio of 1:2:1 (1 resistant, 2 intermediate to 1 susceptible) in the F2 population (table 6 ). Therefore, we concluded that Rhg1 action was codominant. 
Table 6. Phenotypes of individual plants from within RILs and NILs heterozygous and heterogeneous at Rhg1. Resistance is codominant in F2 plants fixed at Rhg4. Rhg4 was fixed at the resistant allele in these populations; E × F34- $(29 \times 6)(\mathrm{F} 1)$ and $\mathrm{E} \times \mathrm{F} 11-3$ (F1) were heterozygotes for Rhg1, the $\mathrm{E} \times \mathrm{F} 11$ and $\mathrm{E} \times \mathrm{F} 34$ series were heterogeneous across the interval carrying Rhg1 (Meksem et al. 1999)

\begin{tabular}{lccccc}
\hline Source population & $\begin{array}{c}\text { FI }<5 \\
\text { \# Resistant plants }\end{array}$ & $\begin{array}{c}5<\mathrm{FI}<40 \\
\text { \# Intermediate plants }\end{array}$ & $\begin{array}{c}\text { FI }>40 \\
\text { \#S Susceptible plants }\end{array}$ & $\begin{array}{c}\text { Ratio } \\
\text { fitted }\end{array}$ & $P$ value \\
\hline E $\times$ F11 series & 10 & 0 & 5 & $3: 1$ & $P<0.05$ \\
E $\times$ F34 series & 17 & 0 & 7 & $3: 1$ & $P<0.05$ \\
E $\times$ F34-(29 $\times 6)(F 2)$ & 5 & 8 & 4 & $1: 2: 1$ & $P<0.05$ \\
E $\times$ F11-3 (F2) & 4 & 7 & 4 & $1: 2: 1$ & $P<0.05$ \\
\hline
\end{tabular}

\section{Discussion}

The low polymorphism between Essex and Forrest is due to the low genetic diversity of the two related cultivars and their pedigrees, and DNA marker analysis shows that they are very closely related (Smith and Camper 1973; Hartwig and Epps 1973; Chang et al. 1997).

Bulked segregant analysis and AFLP identified molecular markers closely linked with the two major QTLs associated with SCN resistance. BSA has been effective for mapping genes which account for $100 \%$ variation in a trait (Michelmore et al. 1991) but is limited in its application to QTL mapping (Darvasi and Soller 1994; Mansur et al. 1996). QTLs with minor phenotypic effects may be heterogeneous in phenotypically selected pools and therefore will escape detection. Using DNA markers distantly linked to the QTLs was effective in selecting members of the pools. Since the sensitivity of the bulked segregant analysis is limited by the length of the target region (Michelmore et al. 1991), lines carrying a recombination event were included in the pools in order to increased the probability of finding more markers close to the targeted loci. The presence of four recombinant lines in the Rhg4 pool prevented the detection of markers mapping outside the 5-cM interval around the Rhg4 locus. The composition of the Rhg1 DNA pool (only 25\% of the lines are recombinants) increased the total number of markers around the QTL but reduced the number of markers in the target region. In fact one-half of the markers detected on linkage group G mapped outside the interval Barc-Satt309-Bng122 proximal to the BARC-Satt214 marker. This is in accordance with the data of Ballvora et al. (1995) and Meksem et al. (1995) who showed that precise targeting can be achieved only if the composition of the pool included recombinants carrying a crossover event in the chromosome segments flanking the target locus at both sides.

The targeted chromosomal intervals around Rhg 1 and $R h g 4$ of $10 \mathrm{cM}$ correspond to $0.3 \%$ of the soybean genome (Cregan et al. 1999a), and about 20\% of the BSA positive markers map to one of the two loci. Sixteen AFLP markers out of 2396 polymorphic AFLP loci were mapped in the 5-cM interval around each Rhg1 and Rhg4. Considering the average distribution of one AFLP marker every 0.5 to $1.5 \mathrm{cM}$, AFLP techniques and bulked segregant analysis are powerful methods for high-density genetic map construction. 
Dominant AFLP markers were linked in coupling on both sides of Rhg1. However, at Rhg4 all AFLP markers detected were dominant, with coupling markers all distal to the locus and repulsion markers all proximal to the gene. This marker structure infers an extensive duplication of the interval containing the Rhg4 locus in this resistant cultivar. Duplication, deletion, unequal exchange, and gene conversion are common events at disease resistance loci (Schnable et al. 1998).

AFLP markers that were in disequilibrium between the pools but not linked to Rhg1 and Rhg 4 were shown to map to two other locations on the genome by linkage to SSR markers. Their loci may represent orthologous regions (Boutin et al. 1995) and carry QTLs for resistance to other races of SCN (Qui et al. 1999), or resistance to non-race 3 sub-populations within the SCN race 3 population (Vierling et al. 1997).

The SSR markers were useful in consolidating the $\mathrm{E} \times \mathrm{F}$ map with the soybean genetic map (Cregan et al. 1999a), and showed that the Rhg1 and Rhg4 fine-mapped loci were on linkage groups $\mathrm{G}$ and A2, respectively. Microsatellite genotyping is slow compared to AFLP; the number of loci detected with one AFLP primer combination is 30-fold higher than by one SSR primer set. However, SSR genotyping was very informative because of its co-dominant nature and ease of use. The codominance is useful for identifying RILs from which to develop NILs from any area of the genome.

Using the most-closely linked DNA markers in the RIL population, $98 \%$ of the SCN resistance phenotype was explained. However, jointly, the two QTLs explained $62 \%$ of the total variation in SCN FI compared to the heritability of $97 \%$. Although we eliminated errors in marker scores, and the variation in SCN FI of the resistance class was small, we did not have linked QTLs or pleiotropism (Knott and Haley 1992; Kearsey and Farquhar 1998) and the two QTLs did not explain all the heritability in the trait. The variability that could not be explained with our genetic markers derives from a wide range of scores within the susceptible class, most likely due to inaccurate counting of the cysts on heavily infested roots. This variability is unlikely to be due to the segregation of minor genes having variable influences for susceptibility because the susceptible control showed the same variability.

Within the NILs, where lines with the Essex allele at both loci were excluded due to the fixation of $R h g 1(\mathrm{E} \times \mathrm{F} 6)$ or $R h g 4(\mathrm{E} \times \mathrm{F} 34)$, the Forrest allele (beneficial allele) explained about $98 \%$ of the variation in SCN FI (table 4 ). Fixation implies that there are no other major QTLs for resistance to SCN race 3 to be discovered in this population. Therefore, resistance to SCN shows bigenic inheritance in Essex $\times$ Forrest. It appears to be a QTL when analyzed with distantly linked markers and using phenotypic data containing variation and error (Knott and Haley 1992; Kearsey and Farquhar 1998). Resistance to SCN race 3 is likely to be bigenic in PI437654 (Webb et al. 1995; Vierling et al. 1997; Prabhu et al. 1999), and Peking (Mahalingam and Skorupska 1995; Chang et al. 1997) when using ideal markers. Resistance to SCN race 3 appears to be monogenic in PI88788 (Concibidio et al. 1997) when using ideal markers. However, the quantitative genetic analysis has identified two dominant genes and one recessive gene conditioning resistance to race 3 in PI88788. This discrepancy may be due to the fact that both authors previously used the Peking line as a direct source of SCN resistance in their crosses (Concibidio et al. 1997) and, in this study, Forrest (which 
derived its SCN resistance from Peking) was crossed to Essex to develop the mapping population.

That both resistance alleles (on linkage groups G and A2) are required for SCN resistance, suggests gene interaction and/or gene complementation (Huang et al. 1997). Further, the Rhg1 resistance gene was co-dominant in agreement with Mansur et al. (1993) rather than recessive as previously suggested (Caldwell et al. 1960; Rao-Arelli et al. 1992). The implication in breeding cultivars for resistance to SCN is that lines selected solely based on the SCN resistance phenotype in early generations are likely to segregate for susceptible plants in later generations due to heterozygous loci. Therefore, selection based on both phenotype and genotype (marker-assisted selection) will be required to ensure a stable resistance. By converting the AFLP markers into single-locus markers, marker-assisted selection for the soybean cyst nematode was successfully improved (Meksem et al. 2001, 2001a).

The genetic populations (Meksem et al. 1999), the AFLP markers, and a large insert DNA library constructed from the resistant parent Forrest (Meksem et al. 1998, 2000a), are currently assisting in the cloning of the two loci Rhg1 and Rhg4.

Acknowledgments - The authors acknowledge J. H. Klein, Dr. Michael Schmidt, Dr. Paul Gibson, and Dr. O Myers Jr., Department of PSGA, Southern Illinois University, for developing the populations and for field management. This research was supported by the United Soybean Board through the "Application of Biotechnology to Control of the Soybean Cyst Nematode" project and the ISPOB "Improving soybean disease resistance by the marker-assisted selection" project.

\section{References}

Ballvora A, Hesselbach J, Niewohner J, Leister D, Salamini F, Gebhardt C (1995) Marker enrichment and a high-resolution map of the segment of potato chromosome VII harbouring the nematode resistance gene Gro1. Mol Gen Genet 249:82-90

Boutin S, Young ND, Olson T, Yu ZH, Shoemaker R, Vallejos (1995). Genome conservation among three legume genera detected with DNA markers. Genome 38:928-937

Caldwell BE, Brim CA, Ross JP (1960) Inheritance of resistance to soybean cyst nematode. Agron J 52:635-636

Chang SJC, Doubler TW, Kilo V, Suttner R, Klein J, Schmidt ME, Gibson PT, Lightfoot DA (1996) Two additional loci underlying durable field resistance to soybean Sudden Death Syndrome (SDS). Crop Sci 36:1684-1688

Chang SJC, Doubler TW, Kilo V, Suttner R, Klein J, Schmidt ME, Gibson PT, Lightfoot DA (1997) Association of field resistance to soybean Sudden Death Syndrome (SDS) and cyst nematode (SCN). Crop Sci 37:965-971

Concibido VC, Boutin S, Denny R, Hautea R., Orf J, Young ND (1996) Targeted comparative genome analysis and qualitative mapping of a major partial resistance gene to the soybean cyst nematode. Theor Appl Genet 93:234-241

Concibido VC, Lange DA, Denny RL, Orf J, Young ND (1997) Genome mapping of soybean cyst nematode resistance genes in Peking, PI90763, and PI88788 using DNA markers. Crop Sci 37:258264 
Cregan PB, Jarvik T, Bush AL, Shoemaker RC, Lark KG, Kahler AL, Kaya N, VanToai TT, Lohnes DJ, Chung J, Specht JE (1999a) The integrated map of the soybean genome. Crop Sci 39:1464-1490

Cregan PB, Mudge J, Fickus EW, Danesh D, Denny R, Young ND (1999b) Two simple sequence repeat markers to select for soybean cyst nematode resistance conditioned by the rhg 1 locus. Theor Appl Genet 99:811-818

Darvasi A, Soller M (1994) Selective DNA pooling for determination of linkage between a molecular marker and a quantitative trait locus. Genetics 138:1365-1373

Hartwig EE, Epps JM (1973) Registration of Forrest soybeans Crop Sci 13:287

Huang N, Parco A, Mew T, Magpantay G, McCouch S, Guiderdoni E, Xu J, Subudhi P, Angeles ER, Kush GS (1997) RFLP mapping of isozymes, RAPD and QTLs for grain shape, brown planthopper resistance in a double haploid rice population. Mol Breed 3:105-113

Hnetkovsky N, Chang SC, Doubler TW, Gibson PT, Lightfoot DA (1996) Genetic mapping of loci underlying field resistance to sudden death syndrome Crop Sci 36:392-400

Kearsey MJ, Farquhar AG (1998) QTL analysis in plants; where are we now? Heredity 80:137-142

Knapp SJ, Bridges WC (1990) Using molecular markers to estimate quantitative trait locus parameters: power and genetic variances for unreplicated and replicated progeny. Genetics 126:769-777

Knott SA, Haley CS (1992) Maximum likelihood mapping of quantitative trait loci using full-sib families. Genetics 132: 1211-1222

Lander E, Botstein D (1989) Mapping Mendelian factors underlying quantitative traits using RFLP linkage maps. Genetics 121:85-199

Lander E, Green P, Abrahamson J, Barlow A, Daley M, Lincoln S, Newburg L (1987) MAPMAKER: aN interactive computer package for constructing primary genetic linkage maps of experimental and natural populations. Genomics 1:174-181

Lark KG, Adler F, Mansur LM, Orf J (1995) Interaction between quantitative trait loci in which trait variation at one locus is conditional upon a specific allele at another. Theor Appl Genet 88:486489

Mahalingam R, Skorupska HT (1995). DNA markers for resistance to Heterodera glycines race 3 in the soybean cultivar Peking. Breed Sci 45:435-445

Mansur LM, Carriquiry AL, Rao-Arelli AP (1993) Generation mean analysis of resistance to race 3 of soybean cyst nematode. Crop Sci 33:1249-1253

Mansur LM, Orf JH, Chase K, Jarvick T, Cregan PB, Lark KG (1996) Genetic mapping of agronomic traits using recombination- events in inbred lines Crop Sci 36:1327-1336

Matthews BF, MacDonald MH, Gebhardt JST, Devine TE (1998) Molecular markers residing close to the Rhg4 locus conferring resistance to soybean cyst nematode race 3 on linkage group A of soybean. Theor Appl Genet 97:1047-1052

Meksem K, Leister D, Peleman J, Zabeau M, Salamini F, Gebhardt C (1995) A high-resolution map of the vicinity of the R1 locus (Phytophtora infestans) on chromosome $\mathrm{V}$ of potato based on RFLP and AFLP markers. Mol Gen Genet 249:74-81

Meksem K, Zhang H-B, Lightfoot DA (1998) A plant transformation ready bacterial artificial chromosome library for soybean: applications in chromosome walking and genome-wide physical mapping. Soybean Genet Newslett 25:139-141

Meksem K, Doubler TW, Chancharoenchai K, Njiti V, Chang SJC, Rao Arelli AP, Cregan PE, Gray LE, Gibson PT, Lightfoot DA (1999) Clustering among loci underlying soybean resistance to Fusarium solani, SDS and SCN in near-isogenic lines. Theor Appl Genet 99:1131-1142 
Meksem K, Zobrist K, Ruben E, Hyten D, Quanzhou T, Zhang H-B, Lightfoot DA (2000a) Two large insert soybean genomic libraries constructed in a binary vector: applications in chromosome walking and genome-wide physical mapping. Theor Appl Genet 101:747-755

Meksem K, Hyten DL, Ruben E, Lightfoot DA (2001a) High-throughput genotyping for the detection of polymorphism physically linked soybean cyst nematode resistance gene Rhg4 using Taqman Probes. Mol Breed 77:63-71

Meksem K, Njiti V, Banz B, Iqbal J, Hyten D, Kassem M, Yuang J, Winters T, Lightfoot DA (2000c) Genomic regions that underlie soybean seed phytoestrogen content. J Biomed Biotechnol 1:35-42

Meksem K, Ruben E, Hyten D, Triwitayakorn K, Lightfoot DA (2001) Conversion of AFLP bands to high-throughput DNA markers. Mol Gen Genet 265 (published online: DOI 10.1007/ ss004380000418)

Michelmore RW, Paran I, Kesseli RV (1991) Identification of markers linked to disease-resistance genes by bulk segregant analysis: a rapid method to detect markers in specific genomic regions using segregating populations. Proc Natl Acad Sci USA 88:9828-9832

Mudge J, Concibido V, Denny R, Young N, Orf J (1996) Genetic mapping of a yield depression locus near a major gene for soybean cyst nematode resistance. Soybean Genet Newslett 23:175-178

Myers GO, Anand SC (1991) Inheritance of resistance and genetic relationships among soybean plant introductions to races of soybean cyst nematode. Euphytica 55:197-201

Njiti VN, Doubler TW, Suttner RJ, Gray LE, Gibson PT, Lightfoot DA (1998) Resistance to soybean sudden death syndrome and root colonization by Fusarium solani f. sp. glycines in nearisogenic lines. Crop Sci 38:422-430

Paterson AH, Lander E, Lincoln S, Hewitt J, Peterson S, Tanksley S (1988) Resolution of quantitative traits into Mendelian factors using a complete RFLP linkage map. Nature 335:721-726

Prabhu RR, Njiti VN, Bell-Johnson B, Johnson JE, Schmidt ME, Klein JH, Lightfoot DA (1999) Selecting soybean cultivars for dual resistance to soybean cyst nematode and sudden death syndrome using two DNA markers. Crop Sci 39:982-987

Qiu BX, Arelli PR, Sleper DA (1999) RFLP markers associated with soybean cyst nematode resistance and seed composition in a 'Peking' × 'Essex' population. Theor Appl Genet 98:356-364

Rao-Arelli AP, Anand SC (1988) Genetic relationships among soybean plant introductions for resistance to race 3 of soybean cyst nematode. Crop Sci 28:650-652

Rao-Arelli AP, Anand SC, Wrather JA (1992) Soybean resistance to soybean cyst nematode race 3 is conditioned by an additional dominant gene. Crop Sci 32:862-864

Riggs RD, Schmidt DP (1988) Complete characterization of the race scheme for Heterodera glycines. J Nematol 20:392-395

Riggs RD, Niblack TL (1999) Soybean cyst nematode. In: Hartman GL, Sinclair JB, Rupe JC (eds) Compendium of soybean diseases. APS Press, St. Paul, pp 52-53

Schnable PS, Hsia AP, Nikolau BJ (1998) Genetic recombination in plants. Curr Opin Plant Biol 1:123129

Shoemaker RC, Specht JE (1995) Integration of the soybean molecular and classical genetic linkage groups. Crop Sci 35:436-446

Skorupska HT, Choi IS, Rao Arelli AP, Bridges WC (1994) Resistance to soybean cyst nematode and molecular polymorphism in various sources of Peking soybean. Euphytica 75:63-70

Smith TJ, Camper HM (1973) Registration of Essex soybeans. Crop Sci 13:495 
Tanksley SD, Nelson JC (1996) Advanced backcross QTL analysis: a method for the simultaneous discovery and transfer of valuable QTLs from unadapted germplasm into elite breeding lines. Theor Appl Genet 92:191-203

Tanksley SD, Ganal MW, Martin GB (1995) Chromosome landing: a paradigm for map-based gene cloning in plants with large genomes. Trends Genet 2:63-68

Vierling RA, Faghihi J, Ferris VR, Ferris JM (1997) Association of RFLP markers with loci conferring broad-based resistance to the soybean cyst nematode (Heterodera glycines). Theor Appl Genet 92:83-86

Vos P, Hogers R, Bleeker M, Reijans M, van de Lee T, Hornes M, Frijters A, Pot J, Peleman J, Kuiper M (1995) AFLP: a new technique for DNA fingerprinting. Nucleic Acids Res 23: 4407-4414

Wang GL, Mackill DJ, Bonman MJ (1994) RLFP mapping of genes conferring complete and partial resistance to blast in a durably resistant rice cultivar. Genetics 136:1421-1430

Webb DM, Baltazar BM, Rao-Arelli AP, Schupp J, Clayton K, Keim P, Beavis WD (1995) Genetic mapping of soybean cyst nematode race-3 resistance loci in the soybean PI 437,654. Theor Appl Genet 91:574-581

Wrather JA, Anderson TR, Arsyad DM, Gai J, Ploper DL, Porta- Puglia A, Ram HH, Yorinori JT (1996) Soybean disease loss estimates for the top ten producing countries during 1994. Plant Dis 81:107110 